\title{
A FORMAÇÃO HUMANA INTEGRAL DIANTE DE RETROCESSOS SOCIAIS
}

\author{
Crislaine Matozinhos Silva Modesto \\ Débora Mazza² (D) \\ Nima Imaculada Spigolon ${ }^{2}$ (D)
}

\begin{abstract}
RESUMO: $\mathrm{O}$ artigo aborda os desafios da formação humana integral, diante da eminência de retrocessos sociais. A partir da análise de fontes documentais e legais, o texto persegue a construção conflituosa e contraditória do Estado democrático de direito expresso na Constituição Federal de 1988, que alçou os direitos sociais ao estatuto de direitos fundamentais. Sugere que a Emenda Constitucional (EC) no 95/2016 representa um retrocesso no campo dos direitos sociais, com consequências imprevisíveis para a democracia, a educação e a educação integral.
\end{abstract}

Palavras-chave: Educação integral. Direito social. Retrocesso social.

\section{The full-time buman formation facing social setbacks}

ABSTRACT: The article addresses the challenges of fulltime human formation, in the face of the eminence of social setbacks. From the analysis of documentary and legal sources, the text pursues the construction of the Democratic State of Law expressed in the Federal Constitution of 1988 that raised social rights to the status of fundamental rights. It suggests that

\footnotetext{
${ }^{1}$ Rede Municipal de Educação - Campinas (SP), Brasil. E-mail: criselcler@gmail.com ${ }^{2}$ Universidade Estadual de Campinas - Campinas (SP), Brasil.

E-mails:dmazza@unicamp.br,nima@unicamp.br

DOI: $10.1590 / C C 0101-32622019219485$
} 
Constitutional Amendment 95/2016 represents a setback in the field of social rights with unpredictable consequences for democracy, education and integral education.

Keywords: Full-time education. Social rights. Social retraction.

\title{
EDUCAÇÃO INTEGRAL: ATUAIS DISCUSSÕES E VELHAS INTENCIONALIDADES
}

\begin{abstract}
discussão sobre a educação integral é necessária, pois compóe as agendas de políticas públicas educacionais nacional 1 e internacional vinculadas à universalização e à melhoria da educação básica (CONFERÊNCIA DE JOMTIEN, 1990; ONU, 1990; DELORS, 1998).
\end{abstract}

Várias foram as tentativas de implementação da educação integral no Brasil, porém elas foram marcadas pela descontinuidade, falta de recursos e alegação de que era onerosa para os cofres públicos (MOLL et al., 2012). Darcy Ribeiro, um dos idealizadores dos Centros Integrais de Educação Pública (CIEPs), ambicionava oferecer ensino público de qualidade em período integral e dizia: "Toda educação pública de qualidade é cara" (RIBEIRO, 1984). No Brasil, as reformas que se seguiram a essas convençôes internacionais foram amplamente justificadas e ancoradas na Constituição de Federal (CF) de 1988, que, desde o seu preâmbulo, anunciava um projeto político de:

Instituir o Estado Democrático que assegure o exercício dos direitos sociais e individuais, a liberdade, a segurança, o bem-estar, o desenvolvimento, a igualdade e a justiça como valores supremos de uma sociedade fraterna, pluralista e sem preconceitos (BRASIL, 1988).

Por meio da CF, os direitos sociais alçaram ao patamar de direitos fundamentais e ganharam contornos definidos: 
Art. 60 São direitos sociais a educação, a saúde, a alimentação, o trabalho, a moradia, o transporte, o lazer, a segurança, a previdência social, a proteção à maternidade e à infância, a assistência aos desamparados (BRASIL, 1988).

A educação, direito social destacado, comparece como:

\begin{abstract}
Art. $208^{\circ}$. O dever do Estado [...] efetivado mediante a garantia da educaçáo básica obrigatória e gratuita dos 4 (quatro) aos 17 (dezessete) anos de idade, assegurada inclusive sua oferta gratuita para todos os que a ela náo tiveram acesso na idade própria (BRASIL, 1988).
\end{abstract}

Como forma de proteger a educação das injunçóes político-partidárias, a lei estabeleceu o Plano Nacional de Educação (PNE) com duração de 10 anos, sinalizando a necessidade de uma política de Estado, e não mais de governo (HOFLING, 2001).

Assim, o processo constituinte apontou a necessidade de buscar soluções para o ensino brasileiro, cujo fracasso expressava-se em taxas de evasão, repetência, distorção idade-série, analfabetismo, escassez de recursos, descontinuidade de políticas e desvalorização do magistério.

Art. 214. [...] o plano nacional de educação, de duraçáo decenal, objetiva articular o sistema nacional de educaçáo em regime de colaboração e definir diretrizes, objetivos, metas e estratégias de implementaçáo para assegurar a manutenção e desenvolvimento do ensino em seus diversos níveis, etapas e modalidades por meio de açôes integradas dos poderes públicos das diferentes esferas federativas que conduzam a I - erradicação do analfabetismo; II - universalizaçáo do atendimento escolar; III - melhoria da qualidade do ensino; IV - formação para o trabalho; $\mathrm{V}$ - promoção humanística, científica e tecnológica do País, VI - estabelecimento de meta de aplicação de recursos públicos em educação como proporção do produto interno bruto (BRASIL, 1988). 
A Lei no 9.394/1996 institui as Diretrizes e Bases da Educação Nacional (LDBEN) e concebe a educação como:

Processos formativos que se desenvolvem na vida familiar, na convivência humana, no trabalho, nas instituiçóes de ensino e pesquisa, nos movimentos sociais e organizaçóes da sociedade civil e nas manifestaçóes culturais (BRASIL, 1996).

Prescreve que a educação escolar se compóe de: "I - educação básica, formada pela educação infantil, ensino fundamental e ensino médio; II - educação superior" (BRASIL, 1996). No entanto, a obrigatoriedade é endereçada ao ensino fundamental e progressivamente à educação básica.

Art. 32 - O ensino fundamental obrigatório, com duração de 9 (nove) anos, gratuito na escola pública, iniciando-se aos 6 (seis) anos de idade, terá por objetivo a formaçáo básica do cidadão, mediante: I - o desenvolvimento da capacidade de aprender, tendo como meios básicos o pleno domínio da leitura, da escrita e do cálculo; II - a compreensão do ambiente natural e social, do sistema político, da tecnologia, das artes e dos valores em que se fundamenta a sociedade; III - o desenvolvimento da capacidade de aprendizagem, tendo em vista a aquisição de conhecimentos e habilidades e a formaçáo de atitudes e valores; IV - o fortalecimento dos vínculos de família, dos laços de solidariedade humana e de tolerância recíproca em que se assenta a vida social (BRASIL, 1996).

Nesse enquadramento, o aumento do tempo escolar no ensino fundamental foi afiançado para induzir o aceleramento da eficiência do sistema educacional. Moll et al. (2012, p. 130) apontam:

O aprofundamento da democracia no Brasil, impóe o enfrentamento das desigualdades sociais historicamente corroboradas pelo sistema educacional por meio da entrada tardia e do percurso interrompido de crianças e 
jovens na escola [...] o debate sobre a ampliação do tempo escolar e da educaçáo integral compóe um conjunto de possibilidades que, a médio e longo prazo, pode contribuir para a modificação de nossa estrutura societária.

A sociedade civil e política, comprometida com a educação nacional, mobilizou-se e instituiu o Fundo de Manutenção e Desenvolvimento do Ensino Fundamental e de Valorização do Magistério (FUNDEF), que vigorou de 1997 a 2006 e foi substituído pelo Fundo de Manutenção e Desenvolvimento da Educação Básica (FUNDEB), em vigor de janeiro de 2007 a 2020, objetivando criar condiçóes de efetivar os dispositivos legais constitucionais. Os fundos vincularam, por lei, um conjunto de produtos contábeis formado por recursos dos três níveis da administração pública do Brasil para promover o financiamento, a manutenção e a valorizaçáo da educaçáo.

A Lei no 10.172, de 9 de janeiro e 2001, institui o Plano Nacional de Educação (BRASIL, 2001) e reconhece que as diretrizes norteadoras da educaçáo fundamental estavam contidas na CF de 1988, na LDBEN no 9.394/1996 e nas Diretrizes Curriculares do ensino fundamental (BRASIL, 2015). Estabeleceu como responsabilidade do poder público a universalização do ensino fundamental a partir da indissociabilidade entre acesso, permanência e qualidade da educação escolar. Indicou que o direito ao ensino fundamental não se restringia à matrícula, mas ao ensino de qualidade até a sua conclusão.

A ampliação progressiva da jornada escolar, de modo a abranger um período de, pelo menos, 7 horas diárias, visava criar condiçóes para regular os percursos escolares, permitir que as crianças e os jovens permanecessem na escola o tempo necessário para concluir o nível de ensino, orientar o cumprimento dos deveres escolares, praticar esportes, erradicar o analfabetismo, reverter a repetência e a evasão, corrigir a distorção idade-série, utilizar o espaço, o tempo e os recursos didáticos de forma a possibilitar e ampliar sociabilidades (BRASIL, 2001).

A Lei $n^{\circ} 13.005 / 2014$ aprova o PNE para o decênio 20142024 e institui em sua "meta 6 - oferecer a educação em tempo integral em, no mínimo, 50\% das escolas públicas, de forma a atender 25\% dos(as) alunos(as) da educação básica” (BRASIL, 2014). 
Considerando as fontes documentais e legais, optou-se por analisar o ordenamento jurídico da educação integral pós-CF de 1988 destacando o contraditório e as ameaças que a Emenda Constitucional (EC) de no 95/2016 interpóe à sua efetivação.

\section{PRINCÍPIO CONSTITUCIONAL DA DIGNIDADE DA PESSOA HUMANA SOB O PRISMA DA POLÍTICA PÚBLICA DE EDUCAÇÃO INTEGRAL}

Entre os princípios fundamentais que compóem o Art. $1^{\circ}, \mathrm{da} C F$ de 1988, destacamos os princípios da cidadania e da dignidade da pessoa humana que desempenham papel central nas jurisprudências nacional e internacional. Eles podem ser tomados como a origem de todos os direitos fundamentais, pois carreiam dimensóes subjetivas e objetivas, investindo os indivíduos de direitos e deveres e impondo determinadas prestaçóes positivas para o Estado. Eles se conectam a um conjunto de prestaçóes materiais consideradas indispensáveis para a vida com dignidade (NUNES, 2010). Entretanto, faz-se necessário destacar que os princípios de cidadania e dignidade humana, assim como do dever do Estado na garantia do direito à educação, não foram tomados como prioridades da nação, vide os conflitos, as disputas e os antagonismos que cercaram, no passado, a luta pela Constituinte e que cercam, no presente, a sua efetivação (FERNANDES, 1989).

Marshall (1967) postula que não existe cidadania sem uma espécie de igualdade humana básica associada com o conceito de participação integral na comunidade e que as desigualdades do sistema de classes sociais náo impedem o reconhecimento de um conjunto de direitos e deveres exercido pelos indivíduos em um Estado.

Diretamente vinculada à cidadania e à dignidade da pessoa humana, a educação comparece "como direito de todos e dever do Estado e da família, será promovida e incentivada com a colaboração da sociedade, visando ao pleno desenvolvimento da pessoa, seu preparo para o exercício da cidadania e sua qualificação para o trabalho" (BRASIL, 1988).

Para tanto, a educação integral no horizonte de Estado democrático de direito, pressupóe um sentimento de estar no mundo 
assegurado por um cinturão de políticas sociais protetoras e progressivas, que promovem relaçóes de pertencimento com os meios social e natural, as dimensóes material e simbólica, as esferas objetiva e subjetiva.

Embora a educação não seja a única responsável por esse engajamento individual e coletivo, ela corrobora a construção de uma nova consciência e uma ordem social mais igualitária e menos violenta (MAZZA, 2016).

É importante que a educação integral conte com a participação dos coletivos extra/intraescolares, particularmente quando se pauta no exercício da cidadania e na dignidade da pessoa humana. Inicialmente, alguns pontos precisam ser analisados, a saber: a infraestrutura escolar está adequada para adaptar-se a um projeto de currículo integrado? Os recursos materiais e humanos atendem à demanda da comunidade escolar? As propostas pedagógicas conseguem efetivar a jornada docente integral em uma única escola? Qual a relação professor/aluno, turma/ sala adequada para que se garanta a diversidade de percursos formativos? Os equipamentos públicos e privados extraescolares podem compor o currículo integrado? O território da escola, do bairro e da cidade tem condições de promover açóes educativas que corroboram a promoção do pleno desenvolvimento da pessoa?

Outra questão que merece reflexão diz respeito ao direito de igualdade legal, presente no art. 5. ${ }^{\circ}$ da CF de 1988. Se todos são iguais perante a lei, faz-se necessário consubstanciar esse direito no plano da igualdade real como princípio de cidadania e pleno exercício da democracia. Nesse diapasão, compreende-se que todos têm o direito à educação visando ao pleno desenvolvimento da pessoa.

Carneiro (2015) entende que "o pleno desenvolvimento da pessoa" consiste em um processo dinâmico que é alcançado continuamente quando a pessoa satisfaz suas necessidades básicas de aprendizagem e de vida. Essas necessidades compreendem tanto os aspectos socioambientais quanto os formais ensinados nas escolas, tais como:

A liberdade de aprender, ensinar, pesquisar e divulgar a cultura, o pensamento, a arte e o saber; o pluralismo de ideias e de concepçôes pedagógicas; o respeito à liberdade e o apreço à tolerância; a valorização da experiência 
extraescolar; a vinculação entre a educação escolar, o trabalho e as práticas sociais; o respeito e a valorização da diversidade étnico-racial (BRASIL, 2015).

\section{EDUCAÇÃO BRASILEIRA: DESAFIOS NA ATUALIDADE}

É preciso destacar que o Brasil experimentou, no período pós-CF de 1988, mais de uma década de crescimento econômico acompanhado de um ordenamento jurídico que lhe permitiu implementar políticas de inserção social e transferência de renda. Nesse cenário, os direitos sociais alçaram ao patamar de direitos fundamentais, passando do plano programático legal para a dimensão pragmática das políticas públicas. Conforme indicado:

Em 1988 o Brasil adotou políticas sociais de caráter universal e vinha logrando reduzir o contingente de miseráveis, além de ter ampliado o acesso da população aos serviços de educação, saúde, previdência, saneamento e assistência social. Também aumentou durante a primeira década do século XXI a proporção de brasileiros com vínculos formais de trabalho, o que contribuiu para melhorar os salários e o acesso dos trabalhadores à previdência social e a benefícios como o seguro-desemprego, entre outros (VIEIRA et al., 2018, p. 6).

Ocorre que, a partir de 2014, o Estado brasileiro, impactado pelas instabilidades globais do modo de produção, circulação e consumo de mercadorias, tem sido acometido por uma severa crise econômica que levou, num primeiro momento, ao processo de impeachment da presidente Dilma, eleita pelo voto popular, processo conduzido pelos poderes legislativo e judiciário, apoiado pela grande mídia e por estratos da população. Instaurou-se no Brasil, a partir de agosto de 2016, um golpe de Estado, que, sob a aparência de combater a corrupção na política, tem pautado uma agenda neoliberal e neoconservadora alinhada ao capital produtivo e financeiro, nacional e internacional, com retrocessos significativos num 
projeto de desenvolvimento nacional tendo em vista um Brasil menos desigual, menos violento e mais democrático (MOLL NETO, 2015). Várias foram as medidas recessivas e de ajuste fiscal com severas restriçóes aos direitos sociais já assegurados (ZAN; MAZZA, 2018).

Entre estes retrocessos, destaca-se a aprovação da EC no 95/2016 - que institui um novo regime fiscal e congela para os próximos 20 anos os investimentos públicos destinados à seguridade social —, que representa um ataque às conquistas democráticas populares ratificadas desde a CF de 1988. Essa EC coloca em risco a manutenção dos direitos sociais em um país marcado por políticas econômicas que promovem muita concentraçáo de riqueza e pouca distribuição de renda e inclusáo social.

Segundo Fagnani (2014) e Saviani (apud RAMOS, 2017), a EC promove um retrocesso conservador, um Estado mínimo e uma política de austeridade com impactos severos sobre a população pobre no Brasil, que perceberá, a curto prazo, uma proteção social inferior à recebida hoje.

Entretanto, uma vez concretizado um conjunto de direitos por meio de vários dispositivos legais do regime democrático, tais restriçóes e retrocessos devem ser analisados não sob a ótica meramente econômica, mas política e jurídica.

Marshall (1967) pontua que o exercício da cidadania configura um patrimônio comum, um sentimento de participação numa comunidade e civilização. Ele diz: "A cidadania compreende a lealdade de pessoas livres, imbuídas de direitos e protegidas por uma lei comum. Seu desenvolvimento é estimulado tanto pela luta para adquirir e proteger tais direitos quanto pelo gozo dos mesmos, uma vez adquiridos" (MARSHALL, 1967, p. 84).

Portanto, cabem à sociedade a construção e a defesa dos contornos desse patrimônio comum, assim como os movimentos de luta para conquistá-lo e protegê-lo. $\mathrm{Na}$ defesa da cidadania e da dignidade humana por ela alcançada, várias entidades têm se manifestado contra a EC no 95/2016 e analisado criticamente o regime de austeridade endereçado ao gasto social.

Recessão, crise econômica e requalificação do estado são alguns dos jargóes que têm ganhado as capas de 
jornais e ocupado espaço no debate público em todo o mundo, mostrando que o debate da austeridade está na ordem do dia. Depois das graves recessóes na Grécia, Irlanda, Portugal, Chipre e Espanha no final da primeira década do novo milênio, de 2015 para cá é o Brasil a bola da vez. Dentre tantas características entre a crise europeia e a brasileira, a pedra de toque que as relaciona é central: o interesse em reduzir a demanda e o direito da maior parcela da sociedade ao acesso e funcionamento do Estado em todos os aspectos, em particular no que tange ao bem-estar social [...] Apesar dos avanços, a receita para o enfrentamento da crise econômica que tem sido amplamente implantada no país limita os avanços obtidos com as políticas sociais de caráter universal e pode retardar a retomada do crescimento, afetando drasticamente o presente e as perspectivas futuras da sociedade brasileira.[...] $\mathrm{O}$ agravamento do arrocho econômico e social, a quebra da institucionalidade com a derrubada da presidente eleita Dilma Rousseff, a disparada da instabilidade política e econômica, e a aprovação da Emenda Constitucional 95, com o congelamento das despesas primárias da União por 20 anos, mostram como o Brasil tem sido usado como laboratório de um ampliado e aprofundado movimento neoliberal e como esse debate é central para a sobrevivência de milhares de brasileiras e brasileiros, cada vez mais excluídos da distribuição social da riqueza (VIEIRA et al., 2018, p. 6-7).

Mas, em qual medida a EC de 2016 fere a CF de 1988 e afeta a educação?

Kelsen (2000) entende que a CF é o documento mais importante do Direito Nacional, aquele que representa "o topo da estrutura hierárquica da ordem jurídica de um Estado” (KELSEN, 2000, p. 186).

A CF de 1988 define-se como sistema de normas e princípios, que regula e institucionaliza juridicamente o fenômeno político e almeja buscar garantias de efetivação. Ela surge num período posterior à ditadura militar; sua elaboraçáo e promulgação são respostas às várias lutas emancipatórias e disputas entre os grupos que compóem a sociedade. É um documento que estabelece progressiva consecução de 
investimentos em políticas sociais que visam o combate à miséria e a redução das iniquidades. Cumpre-nos endossar a observação de Bobbio (2004), quando alega que "sem direitos humanos reconhecidos e protegidos não há democracia, sem democracia não existem condiçóes mínimas para solução pacífica dos conflitos" (BOBBIO, 2004, p. 5).

$\mathrm{O}$ autor alude que o problema fundamental em relação aos direitos humanos, hoje, não é tanto o de justificá-los, mas o de protegê-los. Trata-se de um problema político, e não filosófico. Segundo Bobbio (2004), o problema real que temos de enfrentar, contudo, é o das medidas imaginadas e imagináveis para a efetiva proteção do padrão de direitos alcançado.

Nesse desiderato, Bonavides (2004, p. 187) pressupóe:

O Estado social que temos em vista é o que se acha contido juridicamente no constitucionalismo democrático. Alcançá-lo, foi difícil; conservá-lo, parece quase impossível. E, no entanto, é o Estado a que damos, do ponto de vista doutrinário, valorização máxima e essencial, por afigurar-se-nos como um Estado que busca amortecer a luta de classes e promover a justiça social e a paz econômica.

Diante de tal perspectiva, os direitos sociais, por sua própria natureza, invocam do poder político uma demanda de recursos para sua aplicabilidade plena, o que gera fortes pressóes ideológicas e envolve escolhas políticas determinantes, tendo em vista alcançar o ideal de uma sociedade mais justa e solidária. Paralelamente ao avanço rumo à dilatação dos direitos, aprofunda-se o cenário de desequilíbrio entre receitas, despesas, conflitos de interesses, contradiçóes de classe, disputas entre os diferentes e desiguais. $\mathrm{O}$ Estado, a depender de sua base de sustentação nas tensas relaçóes entre o mercado e o restante da sociedade, muitas vezes opta por realizar contingenciamentos e cortes na agenda de compromissos assumidos. $\mathrm{O}$ ajuste de contas presume a manutenção de despesas consideradas essenciais e a revisão, limitação e eliminação de outras consideradas menos essenciais. O pleito dessa balança é definido no jogo das disputas e dos compromissos políticos. 
Dessa forma, é possível sugerir que a EC de 2016 inviabiliza a efetivação de direitos sociais considerados fundamentais e prescritos na CF de 1988, com consequências imprevisíveis para educação. A EC limita a obrigatoriedade do governo de investir na educação, acarretando efeitos que obstaculizam a implementação do PNE de 2014.

Nesse diapasão, o monitoramento do PNE de 2014 pode ser tomado como bússola da educação no que tange a diretrizes, objetivos, metas, estratégias tendo em vista mensurar o respeito ao direito à educação, a organização de resistência e a consolidação da sociedade democrática (MOLL, 2014; BRASIL, 2018).

O cenário de perda de direitos não se resume ao período de aplicação de metas do PNE, mas às consequências futuras que ultrapassam os próximos 20 anos de exercícios da EC.

Nessa condução, estamos vivenciando um verdadeiro mal-estar constitucional e um pessimismo societário. Vários juristas têm reclamado inserir no texto constitucional o princípio fundamental da Proibição do Retrocesso Social, segundo o qual não pode o Estado extirpar direitos fundamentais já conquistados, ou seja, objetiva proibir a diminuição de proteção aos bens jurídicos fundamentais já alcançados e implementados em determinada sociedade (SARLET, 2008). Verifica-se que os direitos sociais estáo diretamente ligados à cidadania e à dignidade da pessoa humana, assim, o princípio da proibição do retrocesso social representa uma segurança jurídica à preservação dos direitos já adquiridos (SARLET, 2008; VASCONCELLOS; LUIZ, 2015).

Vasconcellos e Luiz (2015) esclarecem que o Princípio da Proibição do Retrocesso Social é uma ferramenta jurídica para proteger os direitos fundamentais, impedindo o Estado de limitar os direitos sociais ou flexibilizá-los.

Para Derbli (2007, p. 290), deve ser evocado:

Particularmente no Brasil, sendo absolutamente necessário que se vislumbre, na Constituição, o princípio que permita a proteção dos patamares já alcançados e consolidados na diária missão de cumprimento do projeto de justiça social delineado pela Constituição - que, por isso, devem ter sua disciplina infraconstitucional minimamente preservada das constantes e bruscas modi- 
ficaçôes que atualmente acometem a realidade política, econômica e social no país e no mundo. No panorama constitucional brasileiro, tal princípio, ao invés de servir de simulacro jurídico para um programa de governo, poderá representar exatamente o contrário: um mecanismo de defesa dos indivíduos em face do exercício do poder político e das cambiantes plataformas de governo.

Paradoxalmente a esses entendimentos, a CF de 1988 preserva ao legislador uma considerável margem de decisão, outorgando-lhe razoável liberdade de conformação e poder de revisibilidade de suas decisóes, porém, a fundamentação de suas decisões deve pautar-se na promoção da justiça social. Além disso, nada o impede que reveja as normativas. Contudo, espera-se que sejam mantidos os princípios de preservação dos direitos já conquistados tanto na esfera legislativa quanto no consenso social.

\section{CONSIDERAÇÕES}

Diante do atual cenário de crise da democracia constitucional no Brasil, consideramos que estamos diante do desmonte do Estado democrático de direito, que se rege pelo pressuposto da defesa dos interesses da maioria da população e da garantia das condiçóes consideradas mínimas para todos. Ele deve assegurar a efetividade de políticas sociais, priorizando as áreas de: educação, saúde, trabalho, lazer, segurança, previdência social e proteção aos desamparados.

Entretanto, no cenário de austeridade e ajuste fiscal, os poderes Executivo, Legislativo e Judiciário estabelecem um teto que congela por 20 anos os gastos públicos destinados às políticas sociais. Esse ato promove retrocessos no escopo dos direitos sociais, inviabiliza a melhoria da educação e estanca a educação integral.

O ajuste fiscal limita os gastos sociais e favorece a concentração de renda, pois não regula os lucros auferidos pelo processo produtivo e pelo capital financeiro nacional e internacional. Constrange as políticas que promovem equidades sociais sem controlar as dinâmicas que aprofundam a exploração e a produção das desigualdades em escala ampliada. 
Essa política já apresentou impactos negativos no aumento da violência nas favelas e ocupaçóes, na vulnerabilidade da população em situação de rua, na realidade das famílias atingidas pela tríplice epidemia (dengue, chikungunya e zika), nas comunidades que vivem da agricultura familiar e da reforma agrária, nas comunidades indígenas, quilombolas, ribeirinhas e da floresta (BRASIL, 2017).

Em tempos de EC, discutir a educação a partir de projetos que apontem para a emancipação humana, a transformação social e a educação integral é uma atitude de resistência para não subordinação dos direitos humanos fundamentais às crises econômicas e instabilidades políticas, pois concebe-os como estratégicos e constitutivos da grandeza de uma nação. Quando são tratados nessa perspectiva, avistam-se retrocessos, com consequências imprevisíveis, nos planos legal e real.

\section{REFERÊNCIAS}

BOBBIO, N. A Era dos Direitos. Tradução de Carlos Nelson Coutinho. Rio de Janeiro: Elsevier, 2004.

BONAVIDES, P. Do Estado Liberal ao Estado Social. 7. ed. São Paulo: Malheiros, 2004. BRASIL. Caderno de Avaliação das Metas do Plano Nacional de Educação: PNE 2014-2024. Brasília: ANPAE, 2018.

. Constituição da República Federativa do Brasil. Brasília: Senado Federal, 1988.

. Emenda Constitucional no 95 de 2016. Brasília: Senado Federal, 2016.

. Lei no 9.394, de 20 de dezembro de 1996 - Diretrizes e Bases da Educaçâa

Nacional. Brasília: Congresso Nacional, 1996.

. Lei no 10.172, de 9 de janeiro de 2001 - Plano Nacional de Educação. Brasília: Congresso Nacional, 2001.

. Lei no 13.005/2014 - Plano Nacional de Educação. Brasília: Congresso Nacional, 2014.

. Relatório sobre o impacto da politica econômica de austeridade nos direitos humanos. Brasília: Plataforma Brasileira de Direitos Humanos, Econômicos, Sociais, Culturais e Ambientais (DESHA), 2017. 
Resolução no 2, $1^{\circ}$ de julho de 2015 - Diretrizes Curriculares Nacionais para a formação inicial em nível superior (cursos de licenciatura, cursos de formação pedagógica para graduados e cursos de segunda licenciatura) e para a formação continuada. Brasília: Ministério da Educação, 2015.

CARNEIRO, M.A. LDB fácil: leitura crítica-compreensiva, artigo a artigo. 23. ed. Petropólis: Vozes, 2015.

CONFERÊNCIA DE JOMTIEN. Declaração Mundial sobre Educação para todos. Tailândia: UNICEF, 1990.

DELORS, J. Educação: um tesouro a descobrir. São Paulo: Cortez; Brasília: MEC/UNESCO, 1998.

DERBLI, F. O Princípio da Proibição de Retrocesso Social na Constituição de 1988. Rio de Janeiro: Renovar, 2007.

FAGNANI, E. Além da Agenda Endógena da Educação: propostas para a construção coletiva de um projeto de desenvolvimento. Educação e Sociedade, Campinas, v. 35, n. 129, p. 999-1026, out./dez. 2014. http://dx.doi. org/10.1590/ES0101-73302014144320

FERNANDES, F. A constituição inacabada. Vias históricas e significado política. São Paulo: Estação Liberdade, 1989.

HOFLING, E. de M. Estado e políticas (públicas) sociais. Cadernos CEDES, v. 21, n. 55, p. 30-41, nov. 2001. http://dx.doi.org/10.1590/S0101-32622001000300003

KELSEN, H. Teoria Geral do Direito e do Estado. Tradução de Luís Carlos Borges. Sáo Paulo: Martins Fontes, 2000.

MARSHALL, T. H. Cidadania, classe social e status. Rio de Janeiro: Zahar, 1967.

MAZZA, D. (org.). Relação entre a universidade pública e a rede municipal de educação: uma experiência formativa. Curitiba: Appris, 2016.

MOLL, J. O PNE e a educação integral: Desafios da escola de tempo completo e formação integral. Retratos da Escola, Brasília, v. 8, n. 15, p. 369-381, jul./dez. 2014. http://dx.doi.org/10.22420/rde.v8i15.447

MOLL, J. et al. Caminhos da educação integral no Brasil: direito a outros tempos e espaços educativos. Porto Alegre: Penso, 2012.

MOLL NETO, R. Diferenças entre neoliberalismo e neoconservadorismo: duas faces da mesma moeda? Rio de Janeiro: Editora UFF, 2015. (Texto didático: Ideologias Políticas.) 
NUNES, L.A.R. O princípio constitucional da Dignidade da Pessoa Humana: doutrina e jurisprudência. 3. ed. São Paulo: Saraiva, 2010.

ORGANIZAÇÃO DAS NAÇÓES UNIDAS (ONU). Estudio Economico para America Latina y el Caribe. Santiago del Chile: ONU, 1990.

RAMOS, Mauro. PEC do Teto dos Gastos inviabilizou a educação pública no país. Jornal Brasil de Fato, 8 dez. 2017. Disponível em: <https://www. brasildefato.com.br/2017/12/08/pec-do-teto-dos-gastos-inviabilizou-aeducacao-pubica-no-brasil-diz-dermeval-saviani/?utm source=bdf\&utm medium=referral\&utm campaign=facebook share $>$. Acesso em: 10 jan. 2018.

RIBEIRO, D. Nossa Escola é Uma Calamidade. Rio de Janeiro: Salamandra, 1984.

SARLET, I.W. Proibição de Retrocesso, Dignidade da Pessoa Humana e Direitos Sociais: manifestaçáo de um constitucional dirigente possível. Revista Eletrônica sobre a Reforma do Estado, Salvador, n. 15, set.-nov. 2008.

VASCONCELLOS, M. de O.; LUIZ, F. V. O Princípio da Proibição do Retrocesso Social e sua Importância na Contemporaneidade. Revista da ESMESC, v. 22, n. 28, p. 39-58, 2015. https://doi.org/10.14295/revistadaesmesc.v22i28.p39

VIEIRA, F.S.; SANTOS, I.S.; OCKÉ-REIS, C.; RODRIGUES, P.H.A. Politicas sociais e austeridade fiscal. Como as políticas sociais são afetadas pelo austericídio da agenda neoliberal no Brasil e no mundo. Rio de Janeiro: Centro Brasileiro de Estudos da Saúde (CEBES), 2018.

ZAN, D.; MAZZA, Débora. Formação de professores no contexto atual: os desafios apontados pelo professor Antonio Nóvoa. In: KRAWCZYK, N. (org.) Escola Pública: tempos difíceis, mas não impossíveis. Campinas: FE/UNICAMP; Uberlândia: Navegando, 2018. p. 187-204.

Recebido em 20 de março de 2019.

Aprovado em $1^{\circ}$ de julho de 2019. 